\title{
Erratum to: Magnetite induces oxidative stress and apoptosis in lung epithelial cells
}

\author{
Vani Ramesh • Prabakaran Ravichandran - Clinton L. Copeland • \\ Ramya Gopikrishnan - Santhoshkumar Biradar • Virupaxi Goornavar • \\ Govindarajan T. Ramesh · Joseph C. Hall
}

Published online: 8 March 2013

(c) Springer Science+Business Media New York 2013

Erratum to: Mol Cell Biochem (2012) 363:225-234
DOI 10.1007/s11010-011-1174-x
We now print the correct version of Fig. 5b.

Everything else in the paper remains correct.

In the original article, the files we received for the four pictures shown in Fig. 5b are incorrect.

Fig. 5 b LE cells were seeded equally and exposed to magnetite $(1,10$, and $20 \mu \mathrm{g})$, cultured for $24 \mathrm{~h}$ and live and dead cells were visualized based on dye-uptake method and photographed. Dead cells were counted, and \% of dead cells were calculated and shown below
(B)

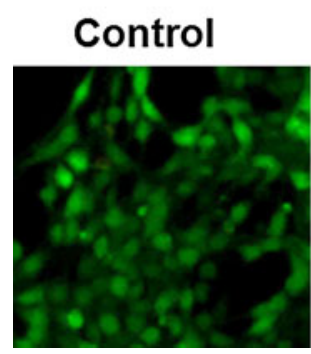

Magnetite

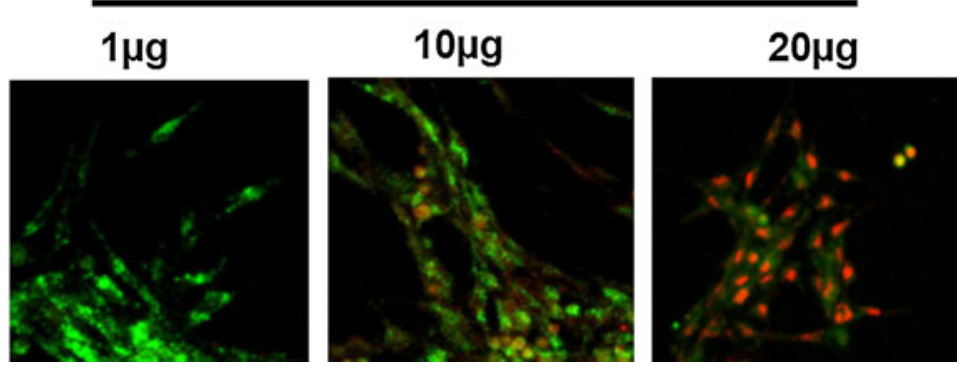

The online version of the original article can be found under doi:10.1007/s11010-011-1174-x.

V. Ramesh · C. L. Copeland · J. C. Hall

Department of Chemistry, Center for Biotechnology \&

Biomedical Sciences, Norfolk State University,

Norfolk, VA 23504, USA

P. Ravichandran · R. Gopikrishnan - S. Biradar .

V. Goornavar · G. T. Ramesh · J. C. Hall ( $\varangle)$

Molecular Toxicology Laboratory, Department of Biology,

Center for Biotechnology \& Biomedical Sciences,

Norfolk State University, Norfolk, VA 23504, USA

e-mail: jchall@nsu.edu 